\title{
Training in the sphere of computational informatics as a condition of developing the informational-computational competence of a would-be informatics teacher
}

\author{
Formação em ciência da computação como uma condição para \\ desenvolver a competência em informação e computação no futuro \\ professor de informática
}

\section{Formación en el ámbito de informática computacional como requisito previo para el desarrollo de la competencia en informática computacional del futuro profesor de informática}

\author{
Guldina Bolshevikovna Kamalova ${ }^{1}$ (D), Bakhytkul Kaskatayeva1 (iD), \\ Shirinkyz Tileubergenovna Shekerbekova ${ }^{1}$ iD , Yelena Anatolievna Kisselyova ${ }^{1}$ iD, \\ Makhabbat Izbasarovna Revshenova ${ }^{1}$ iD
}

${ }^{1}$ Abai University, Almaty, Kazakhstan.

Corresponding author:

Guldina Bolshevikovna Kamalova

Email: g_kamalova@mail.ru

How to cite: Kamalova, G. B., Kaskatayeva, B., Shekerbekova, S. T., Kisselyova, Y. A., \& Revshenova, M. I. (2021). Training in the sphere of computational informatics as a condition of developing the informational-computational competence of a would-be informatics teacher. Revista Tempos e Espaços em Educação, 14(33), e15617.

http://dx.doi.org/10.20952/revtee.v14i33.15617

\begin{abstract}
The huge computational resources of the modern computers are used mainly to solve the problems arising in various applied spheres during mathematical modeling of real objects. These issues are researched in computational informatics. A would-be informatics teacher must have knowledge of it, master the methods of numerical modeling, and be able to teach it to schoolchildren, broadening their knowledge about the possible spheres of using a computer. The informational-computational competence, manifested as the ability and preparedness of a would-be informatics teacher to solve computational problems on a computer and to teach schoolchildren to do it, is one of the most important components of their professional competence. To identify the structure and content of the informational-computational competence of a would-be informatics teacher and to develop the methodology of their training in the sphere of computational informatics ensuring its development. Competence and context approaches to education are used, as well as the concept of funding
\end{abstract}


pedagogical education, as the most effective approaches to developing the informationalcomputational competence of a would-be informatics teacher. The research result is the structurallogical model of the development the informational-computational competence of a would-be informatics teacher during their training in the sphere of computational informatics and the teaching methodology developed on its basis. Implementation of the proposed methodology in teaching computational informatics can provide a would-be informatics teacher with the necessary knowledge and facilitate the development of the informational-computational competence.

Keywords: Competence approach in education. Computational informatics. Informatics education. Informational-computational competence. Training of a would-be informatics teacher.

\section{RESUMO}

A ciência da computação representa uma das áreas científicas da informática, que examina o uso da computação moderna e das tecnologias em modelação numérica dos processos e fenómenos reais. Quando é incorporada no sistema de formação dos professores de informática, ela permite reforçar a solidez da sua formação nesta área, através dos métodos de matemática computacional e técnicas de investigação em ciências da computação incluídos no conteúdo, que são necessários para resolver os problemas computacionais informáticos e, por outro lado, para reforçar a sua orientação aplicada e garantir a possibilidade de uso extensivo dos conhecimentos e competências obtidas na prática, contribuindo assim para o desenvolvimento das suas competências em termos de informação e computação, que se manifesta na capacidade e vontade de resolver tais problemas num computador com a capacidade de escolher as melhores formas de os abordar e o ambiente para os implementar e ensiná-lo aos alunos. O objetivo do estudo é definir a estrutura e o conteúdo da competência em informação e computação do futuro professor de informática e desenvolver os métodos de formação no campo da ciência da computação, os quais garante o seu desenvolvimento. A formação nesta área baseia-se no uso combinado de abordagem por competências e contextual, e no conceito de fundação da formação pedagógica como os mais eficazes para o desenvolvimento da competência em informação e computação de futuro professor de informática. A estrutura e o conteúdo da competência em informação e computação do professor de informática, o modelo do seu desenvolvimento durante a preparação em ciências da computação e o método de ensino que garante o seu desenvolvimento. A competência em informação e computação é uma componente essencial da competência profissional do professor de informática. Como parte do estudo, o método da sua formação em ciência da computação foi desenvolvido, validado e testado, baseando no sistema de tarefas de projeto e tarefas orientadas para a competência, que permite o seu desenvolvimento.

Palavras-chave: Ciência da computação. Competência em informação e computação. Formação de informática. Formação do futuro professor de informática. Metodologia de formação baseada em competências.

\section{RESUMEN}

La informática computacional es uno de los campos científicos de la informática que investiga la aplicación de las técnicas y tecnologías informáticas modernas en la simulación numérica de procesos y fenómenos reales. Su inclusión en el sistema de formación del profesor de informática permite reforzar la fundamentalidad de su formación en el ámbito de informática debido a la inclusión en su contenido los métodos de la matemática computacional y los métodos de investigación científica de la informática necesarios para resolver tareas computacionales por medio del ordenador, y, al mismo tiempo, reforzar su orientación aplicada y asegurar la posibilidad de aplicar ampliamente los conocimientos y habilidades adquiridos en la práctica, contribuyendo así al desarrollo de su competencia en informática computacional, que se manifiesta en la capacidad y disposición para resolver dichas tareas por medio del ordenador, con la posibilidad de elegir los 
mejores métodos de solución y el entorno para su aplicación, y para enseñarlo a los estudiantes. El objetivo del estudio es determinar la estructura y el contenido de la competencia en informática computacional del futuro profesor de informática y desarrollar los métodos de formación en el ámbito de informática computacional para garantizar su desarrollo. La formación en el ámbito analizado se basa en la aplicación combinada de enfoques basados en competencia y contexto, y en el concepto de continuidad de educación pedagógica, como los más eficaces para el desarrollo de la competencia en informática computacional del futuro profesor de informática. La estructura y el contenido de la competencia en informática computacional del profesor de informática, el modelo de su desarrollo en el proceso de formación en el ámbito de informática computacional y los métodos de enseñanza para garantizar su desarrollo. La competencia en informática computacional es uno de los componentes importantes de la competencia profesional del profesor de informática. En el marco del estudio realizado fueron elaborados, fundamentados y probados los métodos de su formación en el ámbito de informática computacional basados en el sistema de tareas orientadas a competencias y a proyectos, proporcionando su desarrollo.

Palabras clave: Competencia en informática computacional. Enfoque basado en competencia en la enseñanza. Formación de futuros profesores de informática. Informática computacional. Educación informática.

\section{INTRODUCTION}

Computational informatics is one of the fields of information science comprising the issues related to research and computer implementation of computational algorithms, applied software for computational problems and methodology of numerical simulation of processes and phenomena (llyin, 1991). These issues constituted the most of informatics content during its formation in the mid 1960-s as the science of information processing automation, as well as in the early years of its development. However, later informatics started to absorb many branches of science related to the research of informational processes and structures. Nevertheless, as the computational capabilities of computers improved, this field of informatics did not lose its significance. Today, in the era of supercomputer, cluster systems and multicore processors, it occupies a special place within informatics, as the most powerful computers are still used to solve the problems arising in various applied spheres in the course of mathematical modeling of actual phenomena and processes (Lapchik et al., 2006). An evidence of this is today's achievements in solving such important tasks atomic, space, economic ones, which would have been impossible without computers and numerical methods. The use of a computer in solving such tasks and the ability to correctly interpret the obtained results require deep understanding of both the computational task to be solved and the selected method for solution. It also requires the knowledge of mathematical modeling and computational experiment methodology, as well as the theoretical principles of numerical calculation algorithms, including precision of number presentation in computer memory (Bidaybekov \& Kamalova, 2007).

There is no doubt that inclusion of computational informatics issues into the system of raining of would-be teachers of informatics enables to form in them an integral vision of informatics as a science, of its position in the modern world and in the system of sciences. Also, it helps to broaden their idea of abilities of a computer, trends and prospects of computer and information technologies' development, means and methods of applying these technologies for solving the computational tasks found in applications. If students are provided with knowledge and skills in the field of solving and teaching to solve computational tasks, they will develop informationalcomputational competence. The latter is manifested in the preparedness and ability to solve and teach to solve computational tasks on a computer and choose the optimal methods of solution and media for their implementation, which they need to efficiently fulfill the informationalcomputational activity during their future professional pedagogical work. 
The sphere of informational-computational activity of an informatics teacher has been significantly broadened in the recent years due to the rapid development of computational technologies and profile differentiation of senior schoolchildren, as natural sciences and mathematical profiles are promoted. Thus, it is topical to develop informational-computational competence in a would-be teacher.

The issues of training of would-be informatics teachers in the sphere of computational informatics have been considered in the works by Bairbekova et al. (2012), Bidaybekov $(2005,2007)$, Fedchenko (2006), Kamalova (2010), Kamalova and Shaybasov 2020), Lapchik et al. (2006), Palchikova (1999), Stepanova (2003). These works in many aspects created the scientific-theoretical and practical basis for solving the problem of preparing pedagogues for professional activity in this field of informatics. In the above works, the conceptual and methodological aspects of training teachers in the said field of informatics were researched in depth, but the issues of developing the informational-computational competence during such training were not sufficiently studied, while they are an important component in the structure of professional competence of a would-be informatics teacher.

The issues of developing and diagnosing the professional competence of specialists in a higher educational establishment were studied in the works by Kirilllov (2005), Butina \& Yakovleva (2018), etc. They emphasize the efficiency of competence-oriented and project-research tasks in promoting the practical focus of training, increasing the professional competence of graduates and its diagnostics.

Admitting the obvious theoretical and practical importance of these works, we should note that the issues of applying such tasks in teaching computational informatics with a view of developing the informational-computational competence of a would-be teacher of informatics have not been studied. Thus, the topicality and importance of the problem, as well as its insufficient elaboration, determined the area of the research.

The main objective of the research is to specify the essence and content of the informationalcomputational competence of a would-be teacher of informatics and to elaborate a methodology ensuring its development in the course of training in the sphere of computational informatics based on a system of competence-oriented tasks and project-research activity.

\section{METHODOLOGY}

Today, many researchers pay special attention to informational-computational competence as one of the key components in the structure of professional competence of an informatics teacher (Kozel \& Karakozov, 2012).

In order to comprehensively study the state of the research problem and reveal the degree of it elaboration, we used a set of mutually supplementing methods: a) theoretical-methodological analysis of psychological-pedagogic, scientific and academic-methodological literature on the research problem; b) analysis of the approaches to the definition and essence of the notion, researching the professional pedagogic activity of an informatics teacher, analysis of the structure of their professional competence, which enabled to specify the notion of informationalcomputational competence of an informatics teacher and to mark out its structural components.

As the performed analysis shows, the said competence refers to special competence of an informatics teacher, developed within the disciplines of their subject training. Similar to the subsystem of the professional competence of an informatics teacher which includes such components of pedagogic activity as motivational-value, cognitive ("knowledge and understanding"), activity ("knowledge how to act"), communicative and reflexive-evaluative components (Bologna process..., 2006; "Pedagog" professional standard, 2017), the informationalcomputational competence has the structure consisting of five interrelated components: motivational-value, cognitive, activity, communicative and reflexive-evaluative, and is assessed by 
their manifestation efficiency in the process of solving the tasks of informational-computational activity.

The motivational-value component reflects the understanding of the studied questions in the sphere of computational informatics for the future professional activity of an informatics teacher; the interest and striving and quality fulfillment of the tasks of informational-computational activity in the future professional pedagogical work; the conscious need for active cognitive work and self-development in this field.

The cognitive component reflects the presence of a system of knowledge and skills in the sphere of solving and teaching to solve computational tasks, which constitute the theoretical basis of informational-computational activity of a teacher; understanding of their world-outlook significance and interdisciplinary character.

The activity component reflects the mastering of methods, means and forms of teaching computational informatics, the ability to actualize the accumulated knowledge and skills in the sphere of computational informatics and to use them as needed, both in academic activity and during implementation of one's professional functions.

It is also important to mark out the communicative and reflexive-evaluative components in the structure of informational-computational competence of an informatics teacher.

The communicative component includes the ability to efficiently use various communication means, including distant ones, when teaching computational informatics, the skills of presenting and defending the results of one's work, argumentatively defend one's position, and the skills of team work, which is essential in teacher's activity.

The reflexive-evaluative component of informational-computational competence is defined as the ability and preparedness for self-analysis and self-control of one's judgments, ability to assess the results of one's activity and, based on them, set the goals and tasks for professional development in this sphere.

The research of the educational potential of computational informatics and the possibilities of using modern technologies and approaches in education allowed revealing the set of pedagogical conditions providing its successful development during training in the sphere of computational informatics. During the research, we used competence and context approaches to teaching and the concept of funding of pedagogical education (Kozyrev \& Radionova, 2004; Kuzminov et al., 2006; Verbitskiy, 2010).

The competence approach, just as the personality- and practice-oriented activity approach, was applied primarily to search for and implement the forms, methods and means of teaching which ensure the development of the students' ability to act autonomously in various problem situations arising during professional activity (Kozyrev \& Radionova, 2004). The context approach to teaching, conceptually describe in the works by Verbitskiy (2010) and his followers, was used to ensure the students' inclusion into diversified pedagogically-oriented activity, which makes the academic work of a would-be teacher maximally close to their professional activity. As for the concept of funding of the pedagogical education content, it was developed by a collective of authors supervised by Shadrikov (Kuzminov et al., 2006; Smirnov, 2012) to provide a close link between the content of training in a pedagogical university and the school course of informatics, as well as to deepen this link during the whole period of training.

One of the key pedagogical conditions for the effective development of informationalcomputational competence of a would-be informatics teacher during their preparation in the sphere of computational informatics is to build the professionally-oriented educational process based on the integration of academic and professionally-oriented project-research activity using the specially designed competence-oriented tasks and professional projects in computational informatics with the clearly specified result of the students' activity. Working on these projects requires the students' ability to autonomously build the research logic, to actualize and integrate 
the accumulated knowledge and skills in various disciplines, to master new knowledge in computational informatics, to study the possibilities of introducing its elements into the school course of informatics, to discuss the arising problem situations, and to exchange information. Implementation of this condition: a) promotes the development of students' cognitive and professional interest to mastering knowledge and skills in computational informatics, comprehension of their necessity for applied fields and for solving informational-computational tasks at school; b) facilitates mastering scientific methods of information research (modeling, computational experiment), methods of computational mathematics and modern digital technologies; forming the skills of using it to solve computational tasks arising when modeling real objects and phenomena, to perform a computational experiment, to teach their learners to do it, and to reflect over one's activity; c) enables to develop important social qualities of a personality, including communicative abilities and the skill of team work, due to group interaction when fulfilling the tasks and the possibility to argumentatively and briefly present their opinions to each other; $d$ ) broadens the intellectual abilities of would-be teachers in general, as well as their ideas about the possible uses of a computer.

The developed knowledge and skills, the experience obtained in the sphere of solving computational tasks with a computer facilitate the development of almost all components of the informational-computational competence and allow a would-be informatics teacher to organize the academic and research work of schoolchildren in the sphere of computational informatics, including with the account of the learners' professional guidance.

Another important condition of the informational-computational competence of a would-be informatics teacher during their preparation in the sphere of computational informatics is interdisciplinary integration, actualization of content links with other disciplines and the school course of informatics.

The computational informatics, represented in the system of training of a would-be informatics teacher mainly by a course "Numerical methods", has horizontal interdisciplinary links with many other disciplines: programming, theoretical informatics, mathematical disciplines, etc., and vertical content links with the fundamental core of the school course of informatics. Implementation of this condition is provided by taking the above links into account in the applied teaching means and inclusion of students into academic and project-research activity. It ensures: a) fundamentalization of the content of a would-be informatics teacher training through deepening the subject knowledge related to solving computational tasks with a computer, due to actualization of horizontal interdisciplinary links with other disciplines of subject training; b) professional orientation of training due to vertical content links with the school course of informatics, influencing the development of actually all components of the informational-computational competence, its cognitive component in particular.

The third condition of development of the informational-computational competence of a would-be informatics teacher during is activation of intersubject relations between a professor and a student during training in computational informatics. Such relations between a pedagogue and a learner supplement and enrich each other's activity, provide the combination of methodological guidance with the development of initiative, independence and self-control of a would-be teacher, their creative, organizational and communicative abilities. At the same time, they significantly influence the development of motivation-value and communicative components.

The fourth condition is purposive work on the development of professional-pedagogical reflection of a would-be teacher during training. The ability of a would-be teacher for reflection and knowledge of its mechanisms allow them to form their own values and to determine the strategy of one's own development, spur to constant self-development and creative attitude to professional activity. At that, during professional training in computational informatics, the constant reflexive analysis of one's activity "should be performed by a would-be teacher from two positions: a learner 
and a teacher, which allows, as early as during training at a pedagogical university, to join in and think over one's future professional activity of teaching, educating and developing a learner's personality" (Raykhert, 2003; Emelina, 2011).

The purposive work on the development of professional-pedagogical reflection of a wouldbe teacher during training in the sphere of computational informatics requires creating a special educational environment, facilitating the appearance of the need for reflection. In particular, it can be achieved by using the teaching methods and techniques which: a) focus not only on the content of training but, to a large extent, on the methods of student's activity; b) facilitate the development of skills in setting and solving problems in the studied field; c) providing a student with the opportunity to act as a teacher explaining the instructional material; to perform reflection of one's activity, individually or in a group, which will undoubtedly influence the development of the reflexive-evaluative component of the informational-computational competence.

The systematizing method in the present research is the method of informational modeling, which allows showing the integral process of developing the informational-computational competence of a would-be informatics teacher during their preparation in the sphere of computational informatics as a structural-logical model, based on the above provisions.

The relevant criteria and indicators of the degree of its development are defined based on Bloom's taxonomy and the professional standard requirements (Khmelnitskaya, 2008; "Pedagog" professional standard, 2017).

\section{RESULTS}

\section{Informational-computational competence of an informatics teacher}

The informational-computational competence of an informatics teacher is an integral professional-personal characteristics including, inter alia, a complex of knowledge, skills, abilities and methods of activity in the sphere of computational informatics and determining a teacher's ability to effectively implement informational-computational activity within the professionalpedagogical work; ensuring the comprehension of the social significance of this type of professional activity of an informatics teacher and their personal responsibility for its results; and the need and possibility for constant self-development and self-education in this field.

Among the basic standard tasks of informational-computational activity, for which a wouldbe informatics teacher must be prepared, one should note solving and teaching to solve computational problems on a computer; ability to choose an optimal numerical method and a software medium for its implementation; building a system of tasks aimed at forming the informational-computational competence in schoolchildren and the ability to assess the degree of its development.

The informational-computational competence of an informatics teacher logically combines the fundamental knowledge in the field of computational informatics, preparedness and ability to apply them in practice when solving and teaching to solve computational problems using modern digital technologies.

The holistic process of developing the informational-computational competence of a wouldbe informatics teacher during their preparation in the sphere of computational informatics can be presented as a structural-logical model, which includes the motivation-value, content, proceduralactivity and control-correctional components; the content and character of the links between the components are determined by the set of the pedagogical conditions described above (Figure 1).

The motivation-value block of the model, which provides the development of the motivation-value component of the informational-computational competence, is based on the students' motives, goals and needs which induce and guide the development process. They are based on comprehension of the significance of the acquired knowledge, skills and experience in the 
sphere of solving computational problems on a computer for the future professional-pedagogic activity.

Figure 1. The model of developing the informational-computational competence of a would-be informatics teacher when training in computational informatics.

Goal: to develop informational-computational competence

Motivation-value block

Content block

School course of informatics

Computational

informatics

Procedural-activity block

Methods:

Means: competence-oriented tasks, professional projects

Control-correctional block

- testing;

- self-analysis;
Disciplines of the subject training of a teacher

Educational result: level of development of informational-

computational competence

The content block ensures the development of the cognitive component of the informational-computational competence and is based on deepening and systematization of the knowledge and skills in the sphere of computational informatics; it is provided by actualization of interdisciplinary links of computational informatics, which is represented in the system of would-be 
informatics teachers' training by one discipline "Numerical methods", with other disciplines of their subject training, as well as content links with the school course of informatics.

The procedural-activity block of the model provides the development of all components of the informational-computational competence, primarily its activity component, due to application of specially selected methods, forms and means of teaching, including competence-oriented tasks and professional projects.

The control-correctional block is aimed at diagnosing the changes taking place during the development of the informational-computational competence. The control methods are combined with self-assessment and self-control, which determines the formation of the reflexive-evaluation components of the informational-computational competence.

The key means of integration of the above-listed structural components of the model are competence-oriented tasks and professional projects. Working over them is the main factor of developing the informational-computational competence of a would-be informatics teacher during training in the sphere of computational informatics and influences the development of all its components.

The influence on the development of the motivation-value component is due, first of all, to their professional orientation, which allows comprehending the value of the acquired knowledge, skills and experience in the sphere of computational informatics for the future professionalpedagogic activity.

The influence on the development of the cognitive component takes place through deepening and systematization of the students' knowledge and skills in the sphere of computational informatics when they work over tasks, due to actualization of the content links of computational informatics with other disciplines and acquaintance with the methods of scientific research.

The development of the activity component is most strongly influenced by the work on competence-oriented tasks and professional projects. It facilitates the formation of professionally necessary research and project skills, as well as the ability to apply the main research methods of informatics - the method of modeling and computational experiment.

The influence on the development of the communicative component occurs as a result of involving the students into team work, possibility to perform various roles when working over a project (such as a head, an executive), to explain the material to other students, to present the obtained results to the group.

The development of the reflexive component is significantly influenced by constant selfanalysis and self-evaluation of the performed work over competence-oriented and project tasks.

The educational result of training in the sphere of computational informatics based on the specially designed competence-oriented tasks and professional projects is the level of development of the informational-computational competence of a would-be informatics teacher.

Analysis of the informational-computational competence of a would-be informatics teacher as a set of its components allows considering the development of each of its components to be criteria of its overall development: motivational-value, cognitive, activity, communicative and reflexive-evaluative. For each of the criteria, it is necessary to determine the indicators that make it possible to assess the degree of their development during training in the sphere of computational informatics.

Based on the above, we elaborated a detailed structure of the informational-computational competence of a would-be informatics teacher, including the criteria and indicators of their development, the latter being determined on the basis of Bloom's taxonomy and requirements of the professional standard of a teacher (Khmelnitskaya, 2008; "Pedagog" professional Standard, 2017) (Table 1). 
Table 1. Criteria and indicators of the level of development of the informational-computational competence of an informatics teacher.

Signs (descriptors)

Criteria Knowledge and understanding

Development of the motivational-value component of the informationalcompetence professional activity; computational

- to explain the significance of the studied issues in the sphere of computational informatics for the future - to prove the need for constant personal and professional selfimprovement in the sphere of computational informatics;

- to realize what information on the issue one possesses and what information one lacks

Development of the cognitive component of the informationalcomputational competence
- to describe the stages of solving a computational problem on a computer; - to describe the methods of solving a computational problem on a computer; - to describe the features of software used for solving a computational problem

- the ability to elaborate a
computational algorithm of
solving the problem, to

describe it as a flow

diagram;

- the ability to implement

the computational

algorithm on a computer: to

write a program in a

programming language,

debug and test it;

- mastering the modern

means of solving

computational problems

Development of the activity component of the informationalcomputational competence

\section{- to explain the essence of} the method of solving a computational problem on a computer;

- to list the abilities and advantages of the software selected for solving a computational problem

\section{- to demonstrate the} preparedness and ability to use the methods of computational mathematics, mathematical modeling and computational experiment, applied software when solving computational problems on a computer

- to demonstrate the mastering of speech culture (ability to correctly and logically speak and write) - to describe information, ideas, problems and solutions in the sphere of computational informatics; - to formulate clearly and unambiguously one's judgments supported with
- the ability to analyze the available information, create a formalized description of a problem (build a mathematical model);

- the ability to execute calculations on a computer (computational experiment), to assess the result obtained

\begin{tabular}{ll}
\hline $\begin{array}{l}\text { Development of the } \\
\text { communicative }\end{array}$ & - to explain the basic \\
notions ad terms from the \\
$\begin{array}{ll}\text { component of the } & \text { sphere of computational } \\
\text { informational- } & \text { informatics }\end{array}$
\end{tabular}

computational competence 
knowledge and skills in the sphere of computational informatics
- the ability to take responsibility for solving problem situations; - the ability to solve organizational problems, distribute work in a group - to analyze and assess the results of one's activity and set the goals of tasks of professional development based on them; - the ability to autonomously prepare a work description, perform a master-class, finalize an article or a report

Table 1 presents the minimally sufficient list of the indicators of the level of development of the students' preparedness for informational-computational activity. It can be expanded as needed by detailing their possible manifestations and signs.

The analysis of the above indicators allowed defining three levels of the development of the informational-computational competence of an informatics teacher: low (reproductive), intermediate (productive) and high (creative). The criterion for these levels is the complexity of tasks which the students are able to sole autonomously.

The low (reproductive) level of the development of the informational-computational competence is the level of perception, comprehension and memorization; it is limited to the categories of "knowledge" and "understanding" by Bloom's taxonomy of pedagogical goals. It implies memorizing and reproducing the studied issues in the sphere of computational informatics, as well as understanding and ability to explain the essence of the studied issues and their importance for the future professional activity; the ability to substantiate the necessity of professional development in this sphere.

The intermediate (productive) level implies applying knowledge according to a model, solving standard problems and explaining them. At this level, the categories of "knowledge" and "understanding" by Bloom's taxonomy of pedagogical goals are supplemented with the intellectual skill of applying the obtained knowledge in a standard situation.

The high (creative) level is the level of applying knowledge in a new situation. It is characterized by additional, higher intellectual skills, such as analysis, synthesis and assessment of the studied issues and results of applying knowledge in practice.

For the quantitative assessment of the level of the development of the informationalcomputational competence, quantitative indicators are introduced in such a way that the weight of each criterion in the overall assessment of the competence development level is equal (for example, 100 scores). It allows determining the level of the development of the informational-computational competence in a student by comparing their average total score with the scale shown in table 2 .

Table 2. Scale of converting the scores into the level of the development of the informationalcomputational competence.

\begin{tabular}{lcccc} 
Level & Inadmissibly low & Low & Intermediate & High \\
Scores & $0-49$ & $50-74$ & $75-89$ & $90-100$ \\
\hline
\end{tabular}




\section{Technique of developing the informational-computational competence of a would-be informatics teacher during training in computational informatics}

Computational informatics as a branch of informatics researching the issues of applying computational technologies for numerical modeling of real processes and phenomena. It is impossible without the modern achievements in computational technologies, which is reflected in the content of training of would-be informatics teachers (Bidaybekov \& Kamalova, 2007). Today, it includes the established classical methods of numerical solution of computational problems and the topical means and techniques of their implementation.

The steady content carcass, or the main content guidelines in the sphere of computational informatics, is defined according to the logic of a computational experiment while solving computational problems arising during mathematical modeling of real processes and phenomena. They comprise the following groups of topics: a) introduction to numerical methods; b) specific features of machine calculations; elementary theory of errors; c) mathematical modeling and computational experiment; d) mathematical apparatus for building and researching computational algorithms; e) modern applied software for computational problems; f) implementation of a sequential computational algorithm; g) issues of organization of parallel computations; $h$ ) parallel generalization of the traditional sequential technique of solving computational problems.

These issues are reflected in the content of a number of disciplines within the subject training of an informatics teacher. First of all, it is the course in "Theoretical informatics" which lays the general theoretical knowledge in informatics, in particular, the basic issues related to the "model-algorithm-program" triad serving as the basis for solving a computational problem.

They are further developed in the "Numerical methods" course. This is one of the most important disciplines in the professional training of a would-be informatics teacher, which develops the concepts of numerical solution of the problems arising during computer mathematical modeling of real phenomena in various spheres (Lapchik et al., 2004). Actually, all the above-listed issues are reflected in its content. They include, first of all, the key notions and essence of the techniques of mathematical modeling and computational experiment, the elements of error theory, and the numerical methods of solving the basic linear algebra problems, to which, as a rule, most computational problems are reduced. Also, they include the basic numerical methods of mathematical analysis and differential equations, as well as processing of experimental data and modern software for their implementation. "This minimum can demonstrate broad possibilities of using mathematical apparatus for studying the real processes and phenomena, at the same time showing the abundance of abilities of computer informational approaches to the reality and their certain fundamental limitations. Most importantly, it should satisfy all needs of an informatics teacher in the sphere of computational informatics and all forms of supplementary and extracurricular work" (Lapchik et al., 2004). Mastering of this course requires fundamental knowledge in the key mathematical disciplines, as well as mastering the modern computer technologies and relevant software.

Below we discuss the topic "Numerical methods of solving the systems of linear algebraic equations".

Solving the systems of linear algebraic equations (SLAE) is one of the most frequent and important problems in applications. Mathematical models of many phenomena and processes are either initially built as linear algebraic systems or reduced to them through discretization or linearization. Rather often they appear to be a part of a large scientific-practical problem within applied research, including in linear programming, econometrics, in the sphere of reverse and illconditioned problems, etc. According to some estimates, they constitute over $70 \%$ of all computational mathematical problems.

Quite often, solving the systems is an ill-conditioned problem when there matrix is rectangular, or square but singular or ill-conditioned. To explain the above in the context of the task 
set, it is appropriate to cite the SLAE examples presented in (Kiryanov \& Kiryanova, 2006). The work considers the problems related to processing the results of an experiment with weighting two objects of two types. For simplicity and distinctness, take apples and pears, each absolutely equal in size. If, according to the problem conditions, one may weigh any number of objects of any type, then the model of any weighing is a linear equation with two unknowns, one of which is the mass of an apple, another is the mass of a pear.

To find these unknowns, one should perform two weighings, for example,

$$
\begin{aligned}
x_{1}+2 x_{2} & =350 \\
3 x_{1}+4 x_{2} & =850
\end{aligned}
$$

According to (1), one apple and two pears are weighed first, then three apples and four pears. Or one may weigh the same amount twice, which is likely to yield different results due to experiment error:

$$
\begin{aligned}
& x_{1}+2 x_{2}=348 \\
& x_{1}+2 x_{2}=351
\end{aligned}
$$

Here the matrix of the system coefficients is singular, unlike in case (1). Its determinant is equal to zero. There may be cases when the matrix of coefficients is not singular but ill-conditioned, and its determinant is not equal to zero but the condition number $|A-1||A|$ is very large $(A$ is the matrix of the system coefficients).

Also, there may be cases when the matrix of coefficients is rectangular, if there were more weighings than the unknowns in order to determine the sought quantities more precisely under the experiment error. For example, in addition to measurements (1), the third weighing was performed with five apples and six pears:

$$
\begin{aligned}
x_{1}+2 x_{2}= & 350 \\
3 x_{1}+4 x_{2}= & 850 \\
5 x_{1}+6 x_{2}= & 1342
\end{aligned}
$$

In some experiments the situation may be reverse - fewer measurements than the unknowns. For example, only one weighing was performed:

$$
x_{1}+2 x_{2}=350
$$

Under such deficit of measurements it is only possible to obtain a solution if there is some additional a priori information on the unknown quantities. As a rule, it can be obtained from the physical meaning of the problem; for example, an apple is on average one and a half times larger than a pear, which can be determined visually.

The examples may seem primitive, but it is important to rather clearly, without using any additional information, demonstrate what kinds of systems of linear algebraic equations can be met in practice and then, apply computational algorithms and be able to explain the result.

Today, computational mathematics possesses a wide range of methods to solve various practical problems with systems of linear algebraic equations, including with specific types of coefficient matrix. To better comprehend them, a rather detailed structural diagram of SLAE solving can be compiled in the interactive form together with students, relying on their knowledge of higher algebra which is studied in the first academic years.

While solving any mathematical problem numerically, it is conventional to study the question of its correctness: whether its solution exists, whether it is unique and steady, i.e. whether it uninterruptedly depends on the input data. Solving SLAE is no exception. It determines the method of its solving. The classical algorithms of SLAE solving, based on the concept of absolute precision, under inevitable errors caused by the limited format of the means applied, cannot be used for solving certain incorrect systems of linear algebraic equations due to their non-robustness to errors. That is why, when solving SLAE, one should first check it for the compatibility according 
to Kronecker-Capelli theorem and its corollaries, which show whether its solutions exist and if they do, how many.

For the systems with a square well-conditioned matrix, the solution exists and it is unique. They quite often appear in everyday calculation, thus there are many methods of solution. The most popular are Gaussian method, used mainly for the systems with dense matrix, simple iteration method, used for the systems with sparse matrix, matrix method (solving the system with a reverse matrix), etc.

In practice, as shown by the above examples, the systems are frequent in which the coefficient matrix is singular or ill-conditioned, often rectangular. Obviously, it is crucial to know the specific features of searching for their solutions. Although the first two types of equations systems significantly differ from each other (the systems with singular matrix have no solution, while the systems with ill-conditioned matrix it exists and it is unique), from the computational point of view they are almost the same. To solve them, a simple but very effective Tikhonov's regularization method is used, based on referring to additional a priori information on the solution, which is often available in practical cases. Another effective method is to use an orthogonal matrix decomposition. As a rule, after a certain decomposition of a matrix, SLAE solution becomes significantly simpler. One of the most popular modern algorithms of arbitrary SLAE solution is singular value decomposition (SVD).

Not less interesting is the solution of systems with rectangular coefficient matrix. If the number of equations in the system is larger than the number of the unknowns, the system is called overdetermined; otherwise, it is called underdetermined. Such systems are also rather frequent in application, especially when processing experiment results.

For overdetermined systems, instead of an accurate solution, one usually searches for the vector which best satisfied all equations in the system, i.e. minimizes their disparity (discrepancy between the left and right parts of the system). This is called a pseudosolution - he vector minimizing the disparity norm of the system of equations. This approach allows, on the one hand, obtaining a physically reasonable solution, and on the other hand - to use the valuable information contained in all equations. As the disparity is a vector value, its norm is minimized, due to practical considerations. As this norm depends on the sum of squares of the components of an unknown vector, the process of searching for a pseudosolution is nothing but implementation of the least squares method.

An alternative is the case of an underdetermined system, which has either infinitely many solutions or no solutions. In the former case, the solution minimal by norm (normal solution) is searched for. The most efficient methods of solving such systems are regularization method and the method based on orthogonal matrix decompositions.

The structural diagram of SLAE solving with an arbitrary matrix of coefficients, as compiled together with students, is shown in figure 2.

This stage of forming the general idea of solving SLAE with an arbitrary matrix of coefficient comprises the cognitive and the academic-professional parts. This is mainly theoretical knowledge in the sphere of solving the systems of linear algebraic equations. For its better mastering, just as with any other theoretical academic material, it is expedient to use active and interactive teaching methods, such as "brainstorming", "teaching others", "discussion", project and research activity, providing inclusion of the educational process participants into various types of cognitive activity (Interactive methods..., 2013; Pulyaevskaya, 2016).

The practical implementation of the described numerical methods is impossible without using the modern informational-communication technologies. We consider specialized mathematical packages (MathCAD, MatLAB, etc.) to be the most promising. Offering a large specter of built-in functions to implement computational algorithms, they provide a visual organization of the computational pattern and allow presentation of the result in various formats. Also, their use in 
training to solve computational problems increases motivation for learning and facilitates interest to the studied material. It is also possible to use MSExcel and programming languages, which allows the would-be informatics teachers to use tasks in computational informatics in the school course of informatics.

Figure 2. Structural diagram of SLAE solving.

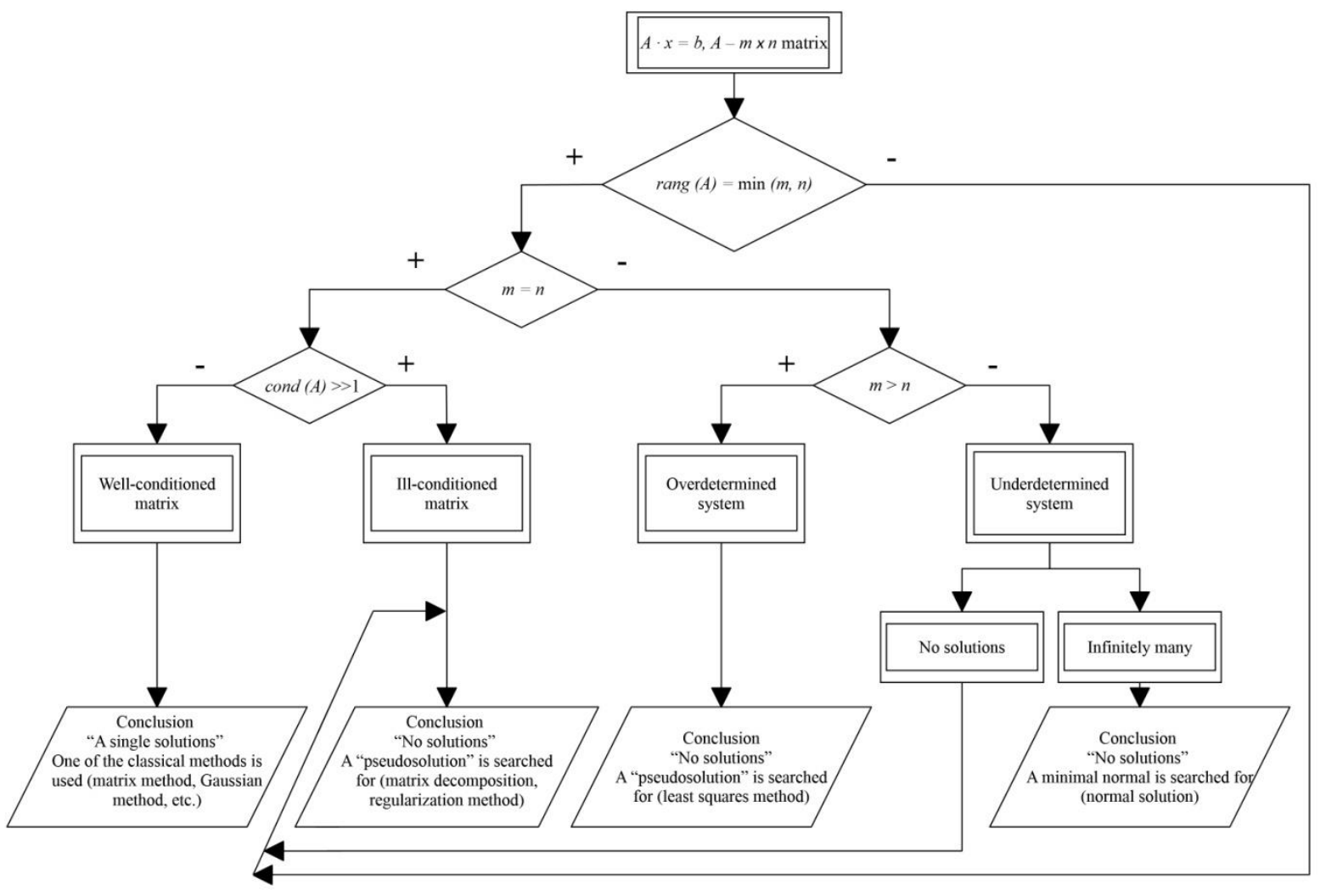

Today, one of the most popular and demanded programming languages is Python. It is included into the school course of informatics and, accordingly, into the curriculum of would-be informatics teachers. A wide range of libraries with a large number of useful functions and possibilities ensure its universal character, thus broadening the spheres of its application. Of special interest are its libraries NumPy and Matplotlib, used for scientific calculations and providing a universal scientific-computational environment, comparable with specialized mathematical packages like MathCAD or MatLab.

As was noted above and shown in figure 2, the choice of SLAE solution method depends on whether the matrix of its coefficient singular or not. In Python, this can be determined with a builtin function linalg.det() of NumPy library.

In case of a square nondegenerate function, the choice of the system solution methods is greatly influenced by the condition number of its coefficients matrix. It estimates the closeness of the matrix to a singular one and serves as an important indicator of the system solution steadiness. The larger the condition number of matrix $A(\operatorname{cond}(A))$, the closer it is to a degenerate one. Taking into account that cond $(A)>=1$, the best condition number is 1 . Systems with ill-conditioned matrices are usually incorrect. Their numerical solution may entail significant error accumulation. For example, if the right part of the system changes insignificantly, the solution error may be rather large. To find the condition number, Python, as well as specialized mathematical software, has a built-in function linalg.cond().

For solving the systems of linear algebraic equations with square nondegenerate matrix, Python has a built-in function linalg.solve(). It implements the matrix method; other methods can 
be implemented autonomously, while the built-in function may be used to check the solution correctness.

The least square method, used to solve overdetermined systems, in implemented in linalg.Istsq() function.

Actually, for each type of coefficients matrix, there is a built-in function. They may be rather convenient to use when we speak of the program implementation of a system with arbitrary coefficients matrix, as they allow reducing the program code and solve the problem in general, without focusing on details (Kamalova, 2020). Also, they can be used to check the correctness of the solution obtained during the program implementation of individual methods.

If there is no built-in function for implementing some methods of solving the systems of linear algebraic equations, there are many additional functions enabling to reduce the program code.

Due to Matplotlib library, which offers great opportunities for visualization of twodimensional and three-dimensional data, it is possible to graphically illustrate the solution of a system of moderate dimensionality.

Training is carried out mostly in the form of lectures, laboratory practice, autonomous work and conferences, including in online format.

\section{DISCUSSION}

Elaborated model of developing the informational-computational competence during training in computational informatics, complemented with a detailed structure of this competence including criteria and indices of its development, may serve as a filter to select the competenceoriented method of education, providing development of this competence and to check the degree of its development in a would-be teacher of informatics.

As practice shows, students - would-be informatics teachers mostly do not possess sufficient mathematical knowledge, hence a large variation of their initial level of preparedness for training in computational informatics; it requires differential and individual approach in teaching. Besides, under the credit form of education introduced to the educational systems of many countries, much time is assigned for autonomous work of students, that is why the process of mastering the study material and developing the informational-computational competence requires high motivation and developed skills of autonomous work. Taking this into account, as well as the fact that competence cannot be transmitted as information but is formed in the process of activity and transformation of one's experience, an effective approach to forming the competence during training in the sphere of computational informatics is by using modern methods and teaching techniques based on competence-oriented tasks and professional projects, which together implement the competence and context approaches in education, as well as the concept of funding the pedagogical education. This approach most fully takes into account the above-listed conditions of training and the individual level of initial preparedness of would-be teachers for mastering the computational informatics and allows involving all learners into the real practice-oriented activity, approximated to their future professional activity.

When studying the topic "Numerical methods of solving the systems of linear algebraic equations" the students get assignments leading to solving SLAE as a result of modeling. For example: "A company manufactures several types of products using raw materials of different types. The information about the amount of raw materials used for each type of products and the stock of each type of the raw materials is shown in table 3 below. Find the planned amount of each type of products if all the available raw materials are used". 
Table 3. Amount and stock of raw materials used for each type of products.

\begin{tabular}{ccccc}
\hline $\begin{array}{c}\text { Type of raw } \\
\text { materials }\end{array}$ & \multicolumn{2}{c}{ Amount of raw materials used for each type of products, per unit } & Stock of raw \\
\cline { 2 - 5 } materials
\end{tabular}

Solving the problem requires performing a computational experiment, including the following stages: 1) building a mathematical model; 2) elaborating a computational algorithm; 3) compiling a program, and implementing it on a computer; 4) analyzing the obtained result.

Denoting the planned amount of the first, second and third types of products as $x 1, x 2$, and $\mathrm{x} 3$, respectively, we get a system of three equations:

$$
\begin{aligned}
& 6 x_{1}+4 x_{2}+5 x_{3}=2400 \\
& 4 x_{1}+3 x_{2}+x_{3}=1450 \\
& 5 x_{1}+2 x_{2}+3 x_{3}=1550
\end{aligned}
$$

For each group of students, the instructor may change the conditions, obtaining systems with various types of coefficient matrices. For example, by removing or adding a type of the available raw materials or changing the number of types of products, one may obtain an overdetermined or underdetermined system.

As practice shows, for the students to better comprehend the main methods of solving the systems of linear algebraic equations with different variants of coefficient matrices (see figure 2) and means of their implementation, the following educational approaches are very effective: A) involving the students into intense cognitive activity in mastering one of the SLAE solution methods, then teaching this method to other students. According to the "learning pyramid" proposed by the followers of Edgar Dale from the National Training Laboratory, USA, this method usually demonstrates high level of mastering the material (Pulyaevskaya, 2016). B) as one problem is solved by different methods for different variants of input data, it is very effective to use parallel learning, which is similar to "parallel information processing" in cybernetics, which means the technique of accelerating the speed of information processing by parallelization. This approach implies parallel learning of each method of SLAE solution by each student group and explaining it to others, which allows mastering the learning material in less time.

Thus, each student group works over an assignment autonomously, parallel with other groups. Having accomplished the task, they report to another group, explaining the solution method they have mastered. While reporting, the students not just exchange the results discuss the solution obtained, but learn to present the selected and systematized material; to build the proof of a hypothesis; to apply the visual means during the presentation; to participate in a group discussion; to analyze the meaning and character of questions; to develop one's idea within the logic of the question posed; to argue one's position; to put counter-questions, etc. While explaining, a student tries on a teacher's role, that being one of the most effective methods to structure and memorize information (Pulyaevskaya, 2016). The algorithms of all solution techniques are better mastered by students than when a professor explains them. Using the parallel learning method significantly decreases the time for learning without reducing the course volume, thus increasing the students' labor productivity.

The level of mastering knowledge and skills is the basis for developing the cognitive component of the informational-computational competence of a would-be informatics teacher. At this stage, the foundation is laid for motivation to learning, interest to the subject and to 
professional pedagogic activity, skill of self-assessment of one's own activity, skill of interaction with other persons and the group, skills of self-teaching and self-education.

One of the requirements to a competence-oriented task is the possibility to apply its solution in the future professional activity. That is why an additional assignment for the above may be to find the practical problems, feasible for schoolchildren, modeled by a system of linear algebraic equations, and to study the possibility of including them into a school informatics course. In such assignments, the students' attention is switched from the academic-subject material to the methodological one. It ensures transformation of cognitive activity into quasi-professional one and the corresponding change of motives, goals, actions, means and results of training.

The skills of correctly formulating tasks and questions, as a rule, ensure successful communication between teachers and learners. The assignments similar to the above emphasize this concept when training a would-be teacher. Due to such organization of training, the educational result acquires a subject character (self-dependence, initiative, responsibility) with conscious actions of students, while the friendly atmosphere and style of interactions promote the motivation for training.

In general, such competence-oriented tasks and organization of working over them facilitate the development of virtually all components of the informational-computational competence. Also, they serve as a convenient tool for controlling the level of its development. That is why during the current control each student solves such a competence-oriented task to develop the informationalcomputational competence up to the appropriate level, while a professor can check the level of its development in a student according to the above-listed criteria and indicators.

Professional projects play a special role in forming the informational-computational competence of a would-be teacher. In particular, they: a) assist to develop self-dependence when mastering new knowledge and applying them in practice; b) allow involving the learners into real practice-oriented activity, aimed at solving the problems oriented towards the future professional interests; c) help to increase the motivational interest of the students in achieving the result; d) ensure creative application of the obtained knowledge, practice-oriented results, reflection and self-assessment.

These advantages of professional projects maximally fit the specificity of training in computational informatics and facilitate the development of all components of the informationalcomputational competence, which testifies to their high efficiency in training. Below we list some of the possible topics of professional projects in the section "Numerical methods of solving the systems of linear algebraic equations" with arbitrary matrix of coefficients: 1) Development of a digital educational resource in Python (or MathCAD) for solving the systems of linear algebraic equations with arbitrary matrix of coefficients, including reference material, a collection of problems, and a calculator. This work allows summarizing the studied material to obtain the integral idea of the topic. The result can be used in practice both in the educational process and in scientific research. 2) Development and implementation of parallel algorithm of solving the systems of linear algebraic equations with arbitrary matrix of coefficients. Assessment of their efficiency. 3) Elements of computational informatics in the school course of informatics. Such topics have a more expressed professional orientation.

Using such competence-oriented and project tasks makes training maximally practiceoriented and allows not only acquiring knowledge but developing skills and competences, implementing one's potential, exchanging experience, setting tasks and finding solutions. Work over them facilitates the development of all components of the informational-computational competence.

Similar tasks are developed and offered to students when teaching all sections of the subject training of would-be teachers in the sphere of computational informatics. The tasks and all associated information are placed in the specially designed network informational-communication 
environment in order to arrange the group work of learners, discuss the results and carry out online consultations. The relevant academic-methodological materials are placed there as well.

The pedagogical experiment, conducted at the Institute for Mathematics, Physics and Informatics of Abai University, showed the positive impact of the developed methodology of training in the sphere of computational informatics, based on competence-oriented tasks and professional projects, on the development of the informational-computational competence of a would-be informatics teacher in compliance with the above-listed criteria and indicators.

\section{CONCLUSION}

To summarize the above, we would like to highlight the great educational potential of computational informatics - one of scientific branches of informatics, which research object is applying the modern computational technologies for numerical modeling of real processes and phenomena. On the one hand, it helps to promote the fundamental character of training of a wouldbe informatics teacher by including the methods of computational mathematics and scientific research into the content of informatics, such as modeling and computational experiment, which are necessary for solving computational problems on a computer; on the other hand, it allows strengthening the applied orientation of informatics and provide the opportunity for the broad application of knowledge and skills in practice, thus broadening the ideas about the abilities of a computer and facilitating the development of informational-computational competence and a number of cognitive skills of a would-be informatics teacher.

The informational-computational competence, manifested, first of all, as the ability and preparedness of a would-be informatics teacher to solve computational problems on a computer and to teach schoolchildren to do it, is one of the essential components in the structure of professional competence of an informatics teacher. The need to develop it in a would-be informatics teacher is due to the fact that the huge computational resources of modern computers are mainly used to solve the tasks arising in various applied spheres in the process of mathematical modeling of real phenomena; hence, a would-be informatics teacher must not only be aware of that but also know the methods and techniques of solving the standard computational problems on a computer, master the skills of solving them and be able to teach schoolchildren to do it, especially at profile level in senior school, thus broadening their ideas about the possible uses of a computer.

The carried out research revealed the pedagogical conditions providing the development of the informational-computational competence of a would-be informatics teacher during training in the sphere of computational informatics; helped to elaborate and substantiate the structural-logical model of its development and to propose a teaching technique ensuring its development based on competence-oriented tasks and professional projects, maximally boosting a student's activity during their implementation. Also, the criteria and indicators for diagnosing the level of its development in a would-be informatics teacher were defined.

The large educational potential of computational informatics is by no means reduced to the above-mentioned aspects. The issues related to training in the sphere of computational informatics require further theoretical and experimental studies. Determining the research prospects, one should note the need to identify the conditions of effective development of the learners' computational thinking and other cognitive skills during training in the sphere of computational informatics, which in the modern digital epoch are considered to be among the main results of education (Standard educational program..., 2019).

Authors' Contributions: Kamalova, G. B.: conception and design, analysis and interpretation of data, and critical review of important intellectual content; Kaskatayeva, B.: conception and design, analysis and interpretation of data, and critical review of important intellectual content; Shekerbekova, S. T.: conception and design, analysis and interpretation of data, and critical review of important intellectual content; Kisselyova, Y. A.: analysis and interpretation of data, and 
critical review of important intellectual content; Revshenova, M. I.: acquisition of data, analysis and interpretation of data, and drafting the article. All authors have read and approved the final version of the manuscript.

Ethics Approval: Not applicable.

Acknowledgments: Not applicable.

\section{REFERENCES}

Bairbekova, G., Nugmanova, S., Kamalova, G., \& Kisseleva, E. (2012). Parallel Computing in Training of Informatics Teachers. Procedia - Social and Behavioral Sciences, 51, 883-887.

Bidaybekov, E. I., \& Kamalova, G. B. (2007). Computational informatics in fundamental training of informatics teachers. Informatizatsiya obrazovaniya - 2007: Materialy Mezhdunarodnoy nauchno-prakticheskoy konferentsii. Part 2. Kaluga: Kaluzhskiy gos. pedagogicheskiy universitet im. K. E. Tsiolkovskogo.

Bidaybekov, E. I., Kamalova, G. B., \& Nugmanova, S. A. (2005). Parallel computing in educational programs of pedagogical universities. Vestnik KazNPU imeni Abaya, 1(12), 64-69.

Bologna process: search for the common features in the European systems of higher education (TUNING project) (2006). Moscow: ITSPKPS.

Butina, Yu. V., \& Yakovleva, A. S. (2018). Competence-oriented tasks when teaching foreign language. Sovremennye problemy nauki i obrazovaniya, 5. Retrieved from: http://www.science-education.ru/ru/article/view?id=28127

Emelina, N. V. (2011). Developing pedagogical reflection of a would-be music teacher. Yaroslavskiy pedagogicheskiy vestnik, 2(3), 166-170.

Fedchenko, G. M. (2006). Methodological system of training the would-be informatics teachers in "Numerical methods". PhD (Pedagogy) thesis. Nizhniy Novgorod.

Ilyin, V. P. (1991). Computational informatics. Novosibirsk: Nauka.

Interactive methods, forms and means of education (methodological recommendations) (2013). Rostov-on-Don. Retrieved from: https://rostov.rpamu.ru/Media/rostov/Svedenia_ob_OO/Obrazovanie/metodicheskie_rekomendacii/interaktiv.pdf

Kamalova, G. B. (2010). Improving teaching of computational informatics as a factor of developing the system training of informatics teachers. Doctoral (Pedagogy) thesis. Almaty.

Kamalova, G. B., \& Shaybasov, K. (2020). On developing a digital resource on numerical methods of solving systems of linear algebraic equations. Materiały XVI Międzynarodowej naukowi-praktycznej konferencji, “Naukowa przestrzeń Europy - 2020, 7, 86-90. Przemyśl: Nauka i studia. Retrieved from: http://www.rusnauka.com/pdf/281267.pdf

Khmelnitskaya, N. I. (2008). Bloom's taxonomy as the basis for assessing the results of teaching students. Sovremennaya vysshaya shkola: innovatsionnyy aspekt, 2, 77-81.

Kirillov, A. G. (2005). Developing professional competencies of a would-be informatics teacher when teaching programming. PhD (Pedagogy) thesis. Shadrinsk.

Kiryanov, D. V., \& Kiryanova, E. N. (2006). Computational physics. Moscow: Polibuk Multimedia.

Kozel, O. N., \& Karakozov, S. D. (2012). Forming an informational-computational competence of a would-be informatics teacher under implementation of the third generation educational standards. Sovremennye problemy nauki i obrazovaniya, 2. Retrieved from: http://www.science-education.ru/ru/article/view?id=6061

Kozyrev, V. A., \& Radionova, N. F. (eds.) (2004). Competence approach in pedagogical education: collective monograph. Saint Petersburg: RGPU named after A. I. Gertsen.

Kuzminov, Ya. I., Matrosov, V. L., \& Shadrikov, V. D. (eds.) (2006). Professional standard of pedagogical activity. Vestnik obrazovaniya, 7.

Lapchik, M. P., Ragulina, M. I., \& Khenner, E. K. (2004). Numerical methods. Moscow: Akademiya.

Lapchik, M. P., Ragulina, M. I., \& Khenner, E. K. (2006). Evolution of the paradigm of applied mathematical training of informatics teachers. Informatika i obrazovaniye, 12, 14-19.

Palchikova, I. N. (1999). Improving the training of would-be informatics teachers in computational mathematics. PhD (Pedagogy) thesis. Saint Petersburg. 
"Pedagog" professional standard (2017). Retrieved from: https://atameken.kz/uploads/content/files/\%D0\%9F\%D0\%A1\%20\%D0\%9F\%D0\%B5\%D0\%B4\%D0\%B0\%D0\%B3\%D0\%B E\%D0\%B3.pdf

Pulyaevskaya, A. (2016). Teaching methods and Dale's pyramid. Retrieved from: https://nitforyou.com/metodped/

Raykhert, T. N. (2003). Teaching the theory of information as a means of fundamentalization of the subject preparation of would-be informatics teachers. PhD (Pedagogy) thesis. Moscow: RGB.

Smirnov, E. I. (2012). Funding in professional training and innovative activity of a teacher. Yaroslavl: Kantsler.

Standard educational program on "Informatics" for grades 10-11 of classes with natural sciences and mathematics / social sciences and humanities profile at the level of comprehensive secondary education with the renewed content (2019). In: Etalonnyy kontrolnyy bank normativnykh pravovykh aktov Respubliki Kazakhstan v elektronnom vide. Retrieved from: https://nao.kz/loader/fromorg/2/25

Stepanova, T. A. (2003). Methodological system of teaching the course "Numerical methods" under informationalcommunication subject environment. PhD (Pedagogy) thesis. Krasnoyarsk.

Silva, L. R., Santos, A. R., \& Santos, I. T. R. (2020). Public policies for education of/in the field and the school environment in a settlement of the MST: the intimate relationship with the pedagogical policy. Journal of Research and Knowledge Spreading, 1(1), e11737.

Verbitskiy, A. A. (2010). Context-competence approach to education modernization. Vyssheye obrazovaniye v Rossii, 5, 32-37.

Received: 21 March 2021 | Accepted: 23 April 2021 | Published: 1 May 2021

This is an Open Access article distributed under the terms of the Creative Commons Attribution License, which permits unrestricted use, distribution, and reproduction in any medium, provided the original work is properly cited. 